\title{
Hyperactivation of L-lactate oxidase by liquid-liquid phase separation
}

Tomoto Ura ${ }^{1,2}$, Ako Kagawa ${ }^{2}$, Hiromasa Yagi $^{2}$, Naoya Tochio ${ }^{2}$, Takanori Kigawa ${ }^{2}$, Tsutomu Mikawa ${ }^{2, *}$, Kentaro Shiraki ${ }^{1, *}$

${ }^{1}$ Faculty of Pure and Applied Sciences, University of Tsukuba, 1-1-1 Tennodai, Tsukuba, Ibaraki 305-8573, Japan.

${ }^{2}$ RIKEN Center for Biosystems Dynamics Research, 1-7-22 Suehiro-cho, Tsurumi-ku, Yokohama 230-0045, Japan

ABSTRACT: Liquid droplets formed by liquid-liquid phase separation are attracting attention as functional states of proteins in living cells. Liquid droplets are thought to activate enzymatic reactions by assembling the required molecules. Thus, liquid droplets usually increase the affinity of an enzyme to its substrates, leading to decreased $K_{\mathrm{M}}$ values. In this study, we demonstrate a new mechanism of enzyme activation in the droplets using L-lactate oxidase (LOX). In the presence of poly-L-lysine (PLL), LOX formed droplets with diameters of hundreds of nanometers to tens of micrometers, stabilized by electrostatic interaction. The enzyme activity of LOX in the droplets was significantly enhanced by a fourfold decrease in $K_{\mathrm{M}}$ and a tenfold increase in $k_{\text {cat. }}$ To our knowledge, this represents the first report for increasing $k_{\text {cat }}$ by the formation of the liquid droplet. Interestingly, the conformation of LOX changed in the liquid droplet, probably leading to increased $k_{\text {cat }}$ value. Understanding enzyme activation in the droplets provides essential information about enzyme function in living cells in addition to biotechnology applications.

\section{Introduction}

Liquid-liquid phase separation has attracted attention as a functional state of proteins in living cells. ${ }^{1}$ The liquid droplets formed by liquid-liquid phase separation compartmentalize biological functions in a crowded cellular environment. The reversible assembly of necessary molecules occurs due to multivalent interactions of intrinsically disordered proteins (IDPs) or nucleic acids. ${ }^{2}$ It has recently been reported that droplets control some intracellular reactions, such as the immune response, ${ }^{3}$ transcription/translation, ${ }^{4,5}$ and carbon dioxide fixation in cyanobacteria. ${ }^{6}$ Because droplets are present in prokaryotes $^{7,8}$ and eukaryotes, they are essential in controlling the biological reactions necessary for life.

The liquid droplets can activate enzyme reactions. ${ }^{1,2,9,10}$ Indeed, enzymes interact favorably with IDPs and nucleic acids. For example, RubisCO, an enzyme of more than $500 \mathrm{kDa}$ for carbon dioxide fixation, functions by forming droplets with a small IDP. ${ }^{6}$ Also, multienzyme assemblies that activate multistep reactions exhibit liquid-like properties, ${ }^{11}$ and they require IDP domains. ${ }^{12}$ Furthermore, many metabolic enzymes act as RNA-binding proteins, ${ }^{13}$ which often form droplets. Some in vitro studies have shown 
that enzymes, such as ribozyme, ${ }^{14}$ kinase,${ }^{15}$ multienzyme complexes, ${ }^{16}$ RNA polymerase and ribosomes, ${ }^{17}$ are activated in droplets. Thus, many kinds of enzymes may form liquid droplets with IDPs or RNAs, leading to changes in enzyme activity within living cells. Although various mechanisms of enzyme activation in droplets have been proposed, ${ }^{9,10}$ the only demonstrated mechanism to date has been compartmentalization. ${ }^{14}$ Thus, we hypothesize that enzyme conformational changes play an important role in activating enzymes within liquid droplets due to a crowded environment.

In this study, we investigated the relationship between enzyme kinetics and liquid droplets using Llactate oxidase (LOX) (Fig. 1). The PLL was used as a model IDP because the sequence of IDP is enriched in charged residues, especially lysine. The liquid droplet of LOX with PLL increased the enzyme activity one order of magnitude or higher than the dispersion state in a buffer solution. The activation of the enzyme in liquid droplets resulted in an increased catalytic constant $\left(k_{\text {cat }}\right)$ of LOX and decreased Michaelis constant $\left(K_{\mathrm{M}}\right)$. The increase of the $k_{\text {cat }}$ was considered to result from the conformational change of LOX in the liquid droplet. The enzyme hyperactivation in liquid droplets has an important implication not only as a control mechanism of the enzyme reaction in living cells but also in industrial applications. 
2. Materials and Methods

\subsection{Materials}

Poly-L-lysine hydrobromide (molecular weight, MW, 4,000-15,000 Da), poly-(D,L)-lysine hydrobromide (MW 25,000-40,000 Da), and 2,6-dichloroindophenol sodium salt hydrate (DCIP) were purchased from Sigma-Aldrich Co. (St Louis, MO, USA). Sodium chloride was obtained from Kanto Chemical Co., Inc. (Tokyo, Japan). Tris(hydroxymethyl)aminomethane was obtained from Nacalai Tesque (Kyoto, Japan), and 2-Morpholinoethanesulfonic acid monohydrate was purchased from Dojindo Lab (Kumamoto, Japan). Rhodamine B isothiocyanate (RBITC) was obtained from Santa Cruz Biotechnology, Inc. (Dallas, TX, USA). LOX was prepared as described previously ${ }^{18}$.

\subsection{Fluorescent labeling of PLL}

PLL labeled with amine-reactive dye RBITC (excitation/emission: 555/580 nm) was prepared per the manufacturer's instructions. Briefly, a solution of RBITC $(1.77 \mathrm{mM})$ in DMSO $(50 \mu \mathrm{L})$ was quickly added to a stirred solution of $20 \mathrm{mM}$ PLL in $20 \mathrm{mM}$ EPPS (950 $\mu \mathrm{L} ; \mathrm{pH} 8.5)$ at room temperature. After the reaction mixture was gently stirred for $1.5 \mathrm{~h}, 200 \mathrm{mM}$ Tris-HCl (100 $\mu \mathrm{L}$; pH 8.5) was added. The PLL-dye conjugates were purified by filtration through Amicon Ultra- $0.5 \mathrm{~mL}$ centrifugal filters with a molecular weight cutoff (MWCO) of $3 \mathrm{kDa}$ (Millipore Sigma). The final concentration of PLL was determined with a bicinchoninic acid (BCA) assay. The number of RBITC molecules conjugated to each LOX enzyme in $10 \mathrm{mM}$ Tris- $\mathrm{HCl}(\mathrm{pH} \mathrm{8.0)}$ was determined from the absorbance at $556 \mathrm{~nm}$ using the molar absorption coefficient $\varepsilon_{556}=87,000 \mathrm{M}^{-1} \mathrm{~cm}^{-1}$. The number of dye molecules per PLL molecule was 0.2 .

\subsection{Enzyme assays}

An enzyme solution containing 0-5 $\mu \mathrm{M}$ LOX and 0-10 mM PLL in $20 \mathrm{mM}$ Tris-HCl and $20 \mathrm{mM}$ MES was prepared and left standing for 20 minutes. A $260 \mu \mathrm{L}$ aliquot of enzyme solution was mixed with a $30 \mu \mathrm{L}$ aliquot of substrate solution containing 0-80 mM L-lactic acid and $15 \mathrm{mM}$ DCIP solution. The initial reaction velocities $\left(v_{0}\right)$ were determined from the slope of the initial decrease in the absorbance at $600 \mathrm{~nm}$ using a JASCO spectrophotometer V-550 (JASCO Co., Ltd, Tokyo, Japan). The normalized enzyme activity was defined as the ratio of $v_{0}$ in the presence of droplets to $v_{0}$ in the absence of droplets.

\subsection{Dynamic light scattering}


Dynamic light scattering (DLS) experiments were performed using a Zetasizer Nano ZS light scattering photometer (Malvern Instruments, Worcestershire, UK) equipped with a $4 \mathrm{~mW}$ He-Ne ion laser $(\lambda=$ $633 \mathrm{~nm}$ ). For determination of the sizes of the enzyme with polyelectrolytes, solutions containing $20 \mathrm{nM}$ LOX, 0-1 mM PLL, $20 \mathrm{mM}$ Tris-HCl, and $20 \mathrm{mM}$ MES were placed in a $1 \mathrm{~cm}$ path length disposable cuvette, and DLS measurements were performed at $25^{\circ} \mathrm{C}$ at a detection angle of $173^{\circ}$. The viscosity of the solutions was approximated by water $(\eta=0.87 \mathrm{cP})$. All results are presented as the mean values of three independent experiments.

\subsection{Optical microscopy}

All images were recorded from an all-in-one fluorescence microscope BZ-X710 (KEYENCE, Osaka, Japan). Aliquots $(100 \mu \mathrm{L})$ of the samples were placed in an ultra-low attachment 96-well plate (Corning, NY, USA). All images were prepared for presentation in BZ-X Analyzer (KEYENCE).

\subsection{Isothermal Titration Calorimetry (ITC)}

ITC experiments were performed on a Microcal Auto-iTC200 calorimeter (Malvern Instruments). The experiments consisted of a series of $0.2 \mu \mathrm{L}$ injections of $4 \mathrm{mM}$ PLL into $200 \mu \mathrm{L}$ of $200 \mu \mathrm{M}$ LOX solution or $1 \mathrm{mM}$ L-lactic acid in the thermostatic cell with an initial delay of $60 \mathrm{~s}$, a $0.4 \mathrm{~s}$ duration of injection, and a spacing of $120 \mathrm{~s}$ between injections. In all cases, the samples were dialyzed in the same buffer of $20 \mathrm{mM}$ Tris- $\mathrm{HCl}$ and $20 \mathrm{mM}$ MES (pH 8) to minimize the interference of mixing and dilution heat signals.

\subsection{Hydrogen-1 nuclear magnetic resonance spectroscopic analysis}

Hydrogen-1 $\left({ }^{1} \mathrm{H}\right)$ nuclear magnetic resonance (NMR) spectra were recorded in $20 \mathrm{mM}$ Tris-HCl buffer at $\mathrm{pH} 8$ (adjusted with $\mathrm{HCl}$ ). Experiments were performed on a Bruker BioSpin Avance III $700 \mathrm{MHz}$ NMR spectrometer at $25^{\circ} \mathrm{C}$.

\subsection{Circular dichroism}

Circular dichroism (CD) experiments were performed in a $1 \mathrm{~cm}$ path-length quartz cuvette using a spectropolarimeter (J-720 W; JASCO Co., Ltd). The enzyme solution containing $1 \mu \mathrm{M}$ LOX and $5 \mathrm{mM}$ Tris$\mathrm{HCl}$ buffer ( $\mathrm{pH} 7.0$ ) was incubated with $1 \mathrm{mM}$ PLL or $1 \mathrm{mM}$ Poly-(D,L)-lysine at $25^{\circ} \mathrm{C}$ for 20 minutes before measurement. The CD spectra of the samples were corrected by subtracting the corresponding spectra of buffers. 


\section{Results}

\subsection{Liquid droplets of LOX and PLL}

LOX has an isoelectric point around $\mathrm{pH}$ 6; hence, it is negatively charged under physiological $\mathrm{pH}$. Because PLL has an isoelectric point of $\mathrm{pH} 10$ and a disordered structure, mimicking IDP, PLL was selected as the pair polymer of LOX. Figure 2 shows the bright-field and fluorescence microscopy micrographs of the sample containing $5 \mu \mathrm{M}$ LOX and $1 \mathrm{mM}$ PLL. To observe LOX and PLL independently, PLL was chemically modified with RBITC (red), whereas intrinsic flavin mononucleotide (green) was used for LOX. Bright-field microscopy showed droplets with spherical structures and diameters of ten micrometers or less (Fig. 2A), indicating the typical appearance of liquid droplets. Fluorescence microscopy revealed that the droplets uniformly contained both LOX and PLL molecules, as judged by green and red fluorescence. Furthermore, LOX-PLL droplets coalesced in approximately $10 \mathrm{~s}$ (Fig. 2B), indicating that the LOX-PLL droplets have liquid-like fluidity.

\subsection{LOX hyperactivation in LOX-PLL droplets}

To investigate the effect of liquid droplets on enzyme activity, we measured the bright-field microscopic images and enzyme activity of LOX under various conditions. In LOX-PLL mixtures containing $5 \mu \mathrm{M}$ LOX with 1-10 mM PLL (Fig. 3A), the LOX-PLL droplets were observed at PLL concentrations above $100 \mu \mathrm{M}$. Spherical droplets formed in the absence of $\mathrm{NaCl}$, whereas the droplets disappeared at above $200 \mathrm{mM} \mathrm{NaCl}$ (Fig. 3B). Thus, LOX-PLL droplets were dependent on $\mathrm{NaCl}$ concentration, indicating that the electrostatic interaction between PLL and LOX plays an important role in droplet formation. Figure 3C shows the microscopic images of LOX-PLL droplets at different $\mathrm{pH}$ values. At $\mathrm{pH}$, only amorphous aggregates were observed. Both amorphous aggregates and liquid droplets were observed at pH 6 and 7, whereas only liquid droplets were observed at pH 8 and 9. These results also demonstrate that the electrostatic interaction between LOX and PLL plays a vital role in forming liquid droplets because LOX has an isoelectric point around $\mathrm{pH} 6$.

The enzyme activities of LOX were measured under each droplet formation condition. The normalized activity of LOX depended on PLL concentration (Fig. 3D), $\mathrm{NaCl}$ concentration (Fig. 3E), and pH change (Fig. 3F). The enzyme activity of LOX was activated a maximum of six times under the condition of droplet formation. A comparison of the enzyme activities in the presence or absence of PLL indicates that the droplet formation plays a crucial role in the activation of LOX.

\subsection{LOX hyperactivation in submicrometer-scale liquid droplets.}


The enzyme activity increased in liquid droplets several tens of micrometers in diameter, but the size of these droplets is comparable to or larger than the size of many living cells. Therefore, we next confirmed whether smaller droplets also have an enzyme-activating effect from a biological perspective. Liquid droplets were observed above 200 nM LOX (Fig. 4A). Furthermore, the enzyme activity of LOX in the presence or absence of $1 \mathrm{mM}$ PLL depended on the concentration of LOX (Fig. 4B). With increasing concentrations of LOX, the enzyme activity was increased regardless of the presence or absence of PLL, but the enzyme activities of LOX with $1 \mathrm{mM}$ PLL were higher than those without PLL, indicating that the enzyme activity of LOX increased in the liquid droplets. It is noted that the activation effect was also observed for 20-100 nM LOX, at which the formation of droplets could not be confirmed by microscopy. Therefore, at $20 \mathrm{nM}$ LOX, we investigated the size of the liquid droplets under various conditions by dynamic light scattering. The particle sizes of LOX-PLL droplets were dependent on PLL concentration, $\mathrm{pH}$, and $\mathrm{NaCl}$ concentrations (Fig. 4C-E). Almost all of the LOX-PLL droplets formed average sizes from $200 \mathrm{~nm}$ to $1,000 \mathrm{~nm}$, depending on the solution conditions. The main driving force of the formation of liquid droplets was the electrostatic interaction between LOX and PLL (Fig. 4E). Furthermore, the normalized activities of LOX depended on PLL concentration, $\mathrm{pH}$, and $\mathrm{NaCl}$ concentrations (Fig. 4F-H). The activities of LOX shown in Figures 4F-H were similar to those of the droplet sizes shown in Figures 4C-E, indicating that the formation of submicrometer-scale liquid droplets also plays an important role in the activation of LOX.

\subsection{Kinetic analysis of LOX in the droplets}

To elucidate the detailed mechanism of LOX activation in the LOX-PLL droplets, we determined the enzyme kinetic parameters of $20 \mathrm{nM} \mathrm{LOX}$ in $20 \mathrm{mM}$ Tris $\mathrm{HCl}$ and $20 \mathrm{mM} \mathrm{MES} \mathrm{buffer} \mathrm{(pH} \mathrm{8.0)} \mathrm{at} 25^{\circ} \mathrm{C}$ (Fig. 5 and Table 1). The $K_{\mathrm{M}}$ of LOX with $1 \mathrm{mM}$ PLL was $0.45 \mathrm{mM}$, approximately fourfold smaller than that without PLL, indicating that the liquid droplet is favorable for binding between LOX and its substrate. Additionally, the $k_{\text {cat }}$ of LOX in the LOX-PLL droplet was approximately tenfold higher than that without liquid droplet, indicating that the turnover number of LOX increased in the liquid droplets. These results indicate that the synergistic effect of both substrate affinity and catalytic turnover activate LOX in the liquid droplets.

\subsection{The interaction between substrate and PLL}

Polymers with opposite charges to the substrate reduce $K_{\mathrm{M}}$ without the formation of liquid droplets. ${ }^{19}$ Because the substrate L-lactic acid is negatively charged, and PLL is positively charged, the interaction between L-lactic acid and PLL may contribute to the decrease in $K_{\mathrm{M}}$ in addition to the formation of liq- 
uid droplets. We therefore investigated the interaction of PLL and L-lactate by isothermal titration calorimetry (ITC) and NMR. The titration of L-lactate into the PLL solution showed no significant changes during the titration (Fig. 6A), indicating that L-lactate did not bind to PLL. By contrast, the titration of LOX into PLL solution showed a large positive value with a maximum enthalpy of $0.7 \mathrm{kcal} / \mathrm{mol}$ (Fig. 6B). This was due to the entropy-driven behavior observed during the formation of polymer complexes by electrostatic interactions. ${ }^{20}$ For confirmation of the binding between L-lactate and PLL, ${ }^{1} \mathrm{H}-\mathrm{NMR}$ spectrum of L-lactate was performed in the presence or absence of PLL (Fig. 6C). L-lactate alone was assigned by three peaks ranging 1.22-1.24, 1.34-1.38, and 1.48-1.50 ppm. The addition of PLL to the L-lactate solution did not change the intensities or the chemical shifts of these peaks. These results also indicate that L-lactate does not interact with PLL. Thus, liquid droplets may play an essential role in increasing the affinity between the substrate and enzyme, rather than between the substrate and the PLL scaffold.

\subsection{Secondary structure of LOX in the liquid droplets}

Because the increase in $k_{\text {cat }}$ may be due to the conformational change of LOX within the liquid droplets, we next investigated the conformational change of LOX in the liquid droplet by examining the secondary structure of LOX via the far-ultraviolet (UV) circular dichroism (CD) spectrum. The far-UV CD spectra of LOX showed negative peaks at 208 and $218 \mathrm{~nm}$, and that of PLL showed positive absorption peaks at 210-230 nm (Fig. 7A). Far-UV CD spectra of the mixture of LOX and PLL did not match that calculated from the individual spectra of LOX and PLL alone (Fig. 7B). These results suggest that some of the structural changes of LOX or PLL were induced by their interaction.

PLL or LOX alone showed large far-UV CD ellipticity (Fig. 7A). Thus, we employed poly-(D,L)-lysine (PDLL), which is achiral in CD measurements, to detect subtle changes in the secondary structure of LOX (Fig. 7C). As expected, PDLL showed almost no far-UV CD spectrum due to its lack of optical activity (Fig. 7C). In the presence of $1 \mathrm{mM}$ PDLL, at which LOX and PDLL formed a liquid droplet and showed hyperactivation (Supplementary Fig. S1), the spectrum of LOX drastically changed. Notably, the intensity of LOX at $210 \mathrm{~nm}$ was higher than that in the absence of PDLL. These results indicate that a conformational change of LOX was induced in the liquid droplet, which may cause its increased $k_{\text {cat. }}$ 


\section{Discussion and conclusion}

Here, we reported that the enzyme activity of LOX in liquid droplets was extremely enhanced compared with that in the dispersion state. The LOX-PLL droplets were mainly stabilized by electrostatic interactions between anionic LOX and cationic PLL (Figs. 3 and 4). The mechanism of LOX enzyme activation might be derived from the kinetic parameters (Fig. 5 and Table 1) and conformational properties (Fig. 7). Briefly, the formation of liquid droplets decreased $K_{\mathrm{M}}$ due to the compartmentalization of substrates in the liquid droplet, not due to the interaction between substrate and PLL (Fig. 6). Interestingly, the liquid droplets increased $k_{\text {cat }}$ about tenfold higher than the buffered solution. To our knowledge, this is the first report of increased $k_{\text {cat }}$ in liquid droplets. The activation of LOX in the liquid droplets resulted from its conformational change, as suggested by the CD results (Fig. 7).

Enzyme activation by the formation of liquid droplets may result from one or more of the following possibilities. First, the interaction of the enzyme with the polymer in the liquid droplets may increase the structural stability of the native enzyme, leading to an increased $k_{\text {cat. }}{ }^{21-23}$ Second, liquid droplets are highly crowded with macromolecules, resulting in the exclusion of water molecules. This crowding stabilizes nonnative structures that differ from those in dilute conditions. ${ }^{24}$ Therefore, the crowding effect may promote the transition state of the enzyme, leading to the enhancement of enzyme activity. Finally, liquid droplets represent a nonpolar environment compared with a buffered solution. ${ }^{25}$ A nonpolar solution increases the stability of hydrogen bonds and electrostatic interactions, which influence enzyme activity. Furthermore, LOX has a disordered loop and a short helix that control enzyme activity. ${ }^{26,27}$ These mobile regions cover the active center, and hence the flexibility of the regions contribute to the activation enzyme, such as substrate uptake, product release, and the formation of an active site microenvironment. Specifically, the hydrogen bond network in the active site and product pyruvate play important roles in the activity of LOX. The CD results show that the percentage of LOX $\alpha$-helix within the droplet was reduced, indicating changes in the structure and dynamics of this region within the droplet. Further structural analysis of this region within droplets will be an interesting subject for future research.

The activation of LOX within liquid droplets is valuable information for industrial applications. Currently, the primary method of enzyme activation is protein engineering ${ }^{28}$ and directed evolution. ${ }^{29}$ These $^{2}$ methods create favorable mutants with high activity by repeated mutation introduction and screening. However, they are time-consuming and costly to produce desirable mutants. By contrast, the formation of liquid droplets is a simple method for improving enzyme activity because only the addition of a polyelectrolyte into the enzyme solution is needed. LOX is an oxidoreductase applied to biofuel cells ${ }^{18}$ and 
biosensors. ${ }^{30}$ Thus, the formation of liquid droplets represents a versatile approach for improving enzyme activity for practical applications using LOX or other enzymes.

\section{AUTHOR INFORMATION}

\section{Corresponding Author}

*Tsutomu Mikawa: E-mail: mikawa@riken.jp Tel: +81-45-633-8013. Fax: +81-45-503-9643.

*Kentaro Shiraki: E-mail: shiraki@bk.tsukuba.ac.jp. Tel: +81-29-8535306. Fax: +81-29-8535215.

\section{ORCID}

Tsutomu Mikawa: 0000-0003-2325-5084

Kentaro Shiraki: 0000-0003-3438-4076

\section{ACKNOWLEDGMENT}

This work was partially supported by JST-ASTEP (Grant No. AS272S004a) to T.M.. This work was partly supported by JSPS KAKENHI (Grant No. 18H02383 and 18H01719) to K.S..

\section{REFERENCES}

1 Y. Shin and C. P. Brangwynne, Science, 2017, 357, eaaf4382.

2 S. F. Banani, H. O. Lee, A. A. Hyman and M. K. Rosen, Nat. Rev. Mol. Cell Biol., 2017, 18, 285-298.

3 M. Du and Z. J. Chen, Science, 2018, 361, 704-709.

4 D. Hnisz, K. Shrinivas, R. A. Young, A. K. Chakraborty and P. A. Sharp, Cell, 2017, 169, $13-23$.

5 T. H. Kim, B. Tsang, R. M. Vernon, N. Sonenberg, L. E. Kay and J. D. Forman-Kay, Science, 2019, 365, 825-829.

6 H. Wang, X. Yan, H. Aigner, A. Bracher, N. D. Nguyen, W. Y. Hee, B. M. Long, G. D. Price, F. U. Hartl and M. Hayer-Hartl, Nature, 2019, 566, 131-135.

7 N. Al-Husini, D. T. Tomares, Z. J. Pfaffenberger, N. S. Muthunayake, M. A. Samad, T. Zuo, O. Bitar, J. R. Aretakis, M. H. M. Bharmal, A. Gega, J. S. Biteen, W. S. Childers and J. M. Schrader, Mol. Cell, 2020, 78, 670-682.e8. 
8 M. C. Cohan and R. V. Pappu, Trends Biochem. Sci., 45, 668-680, 2020.

9 W. Stroberg and S. Schnell, Biophys. J., 2018, 115, 3-8.

10 K. K. Nakashima, M. A. Vibhute and E. Spruijt, Front. Mol. Biosci., 2019; 6: 21

11 D. L. Schmitt and S. An, Biochemistry, 2017, 56, 3184-3196.

12 M. Jin, T. Han, Y. Yao, A. F. Alessi, M. A. Freeberg, K. Inoki, D. J. Klionsky, J. K. Kim, M. Jin, D. J. Klionsky, T. Han, M. A. Freeberg, A. Karnovsky, J. J. Moresco, J. R. Yates, M. Baba, A. D. Gitler, K. Inoki, G. G. Fuller, A. F. Alessi, M. A. Freeberg, N. P. Roach, J. K. Kim and T. Han, Cell Rep., 2017, 20, 895-908.

13 A. Castello, M. W. Hentze and T. Preiss, Trends Endocrinol. Metab., 2015, 26, 746-757.

14 C. A. Strulson, R. C. Molden, C. D. Keating and P. C. Bevilacqua, Nat. Chem., 2012, 4, 941-946.

15 S. Koga, D. S. Williams, A. W. Perriman and S. Mann, Nat. Chem., 2011, 3, 720-724.

16 J. Crosby, T. Treadwell, M. Hammerton, K. Vasilakis, M. P. Crump, D. S. Williams and S. Mann, Chem. Commun., 2012, 48, 11832-11834.

17 E. Sokolova, E. Spruijt, M. M. K. Hansen, E. Dubuc, J. Groen, V. Chokkalingam, A. Piruska, H. A. Heus and W. T. S. Huck, Proc. Natl. Acad. Sci., 2013, 110, 11692-11697.

18 I. Shitanda, K. Takamatsu, A. Niiyama, T. Mikawa, Y. Hoshi, M. Itagaki and S. Tsujimura, J. Power Sources, 2019, 436, 226844.

19 T. Kurinomaru, S. Tomita, Y. Hagihara and K. Shiraki, Langmuir, 2014, 30, 3826-3831.

20 L. W. Chang, T. K. Lytle, M. Radhakrishna, J. J. Madinya, J. Vélez, C. E. Sing and S. L. Perry, Nat. Commun., 2017, 8, 1273

21 T. Kurinomaru, T. Kameda and K. Shiraki, J. Mol. Catal. B Enzym., 2015, 115, 135-139.

22 M. J. Thiele, M. D. Davari, M. König, I. Hofmann, N. O. Junker, T. Mirzaei Garakani, L. Vojcic, J. Fitter and U. Schwaneberg, ACS Catal., 2018, 8, 10876-10887.

23 E. H. Lee, T. Tsujimoto, H. Uyama, M. H. Sung, K. Kim and S. Kuramitsu, Polym. J., 2010, 42, 818-822.

24 R. Harada, N. Tochio, T. Kigawa, Y. Sugita and M. Feig, J. Am. Chem. Soc., 2013, 135, 36963701.

25 T. J. Nott, E. Petsalaki, P. Farber, D. Jervis, E. Fussner, A. Plochowietz, T. D. Craggs, D. P. Bazett-Jones, T. Pawson, J. D. Forman-Kay and A. J. Baldwin, Mol. Cell, 2015, 57, 936-947.

26 T. Stoisser, M. Brunsteiner, D. K. Wilson and B. Nidetzky, Sci. Rep., , DOI:10.1038/srep27892.

27 T. Stoisser, M. Klimacek, D. K. Wilson and B. Nidetzky, FEBS J., 2015, 282, 4130-4140.

28 M. Goldsmith and D. S. Tawfik, Curr. Opin. Struct. Biol., 2017, 47, 140-150.

29 U. T. Bornscheuer and M. Pohl, Curr. Opin. Chem. Biol., 2001, 5, 137-143. 
bioRxiv preprint doi: https://doi.org/10.1101/2020.12.08.416958; this version posted December 9, 2020. The copyright holder for this preprint (which was not certified by peer review) is the author/funder, who has granted bioRxiv a license to display the preprint in perpetuity. It is made available under aCC-BY-NC-ND 4.0 International license.

30 P. Bollella, S. Sharma, A. E. G. Cass and R. Antiochia, Biosens. Bioelectron., 2019, 123, $152-$ 159. 


\section{Dispersion state}

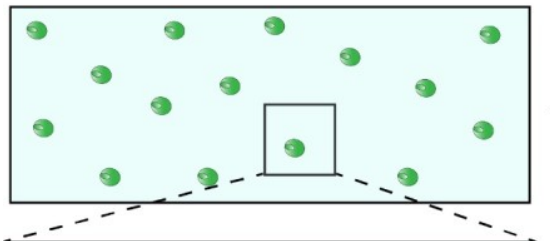

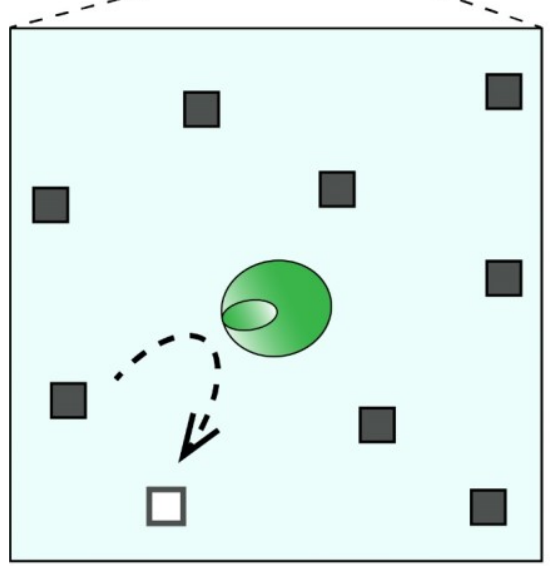

Low activity
Liquid droplets
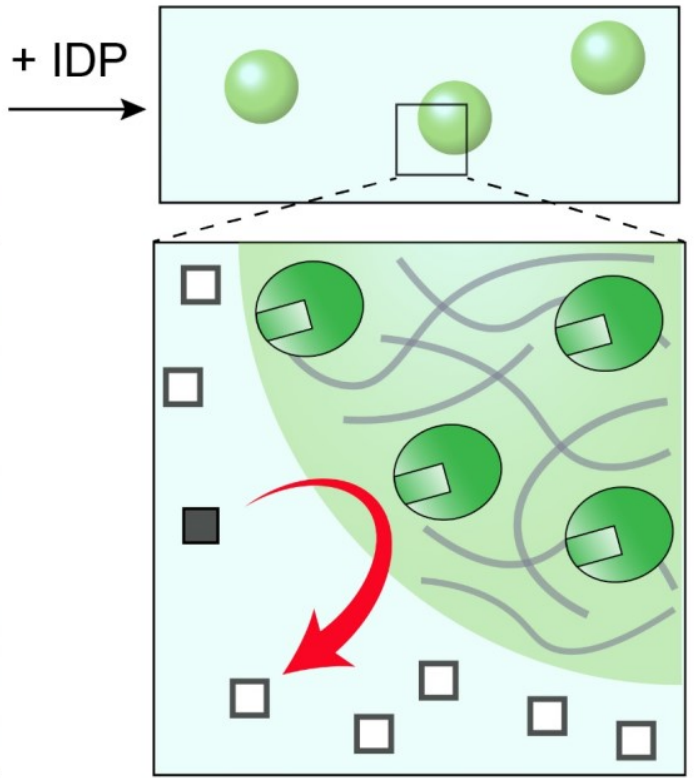

High activity

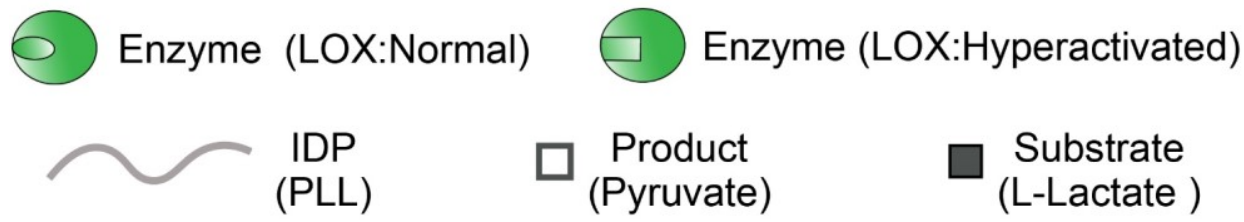

Figure 1. Schematic diagram of enzyme reactions in dispersion state or liquid droplets. Poly-L-lysine (PLL) mimics intrinsically disordered protein (IDP). 

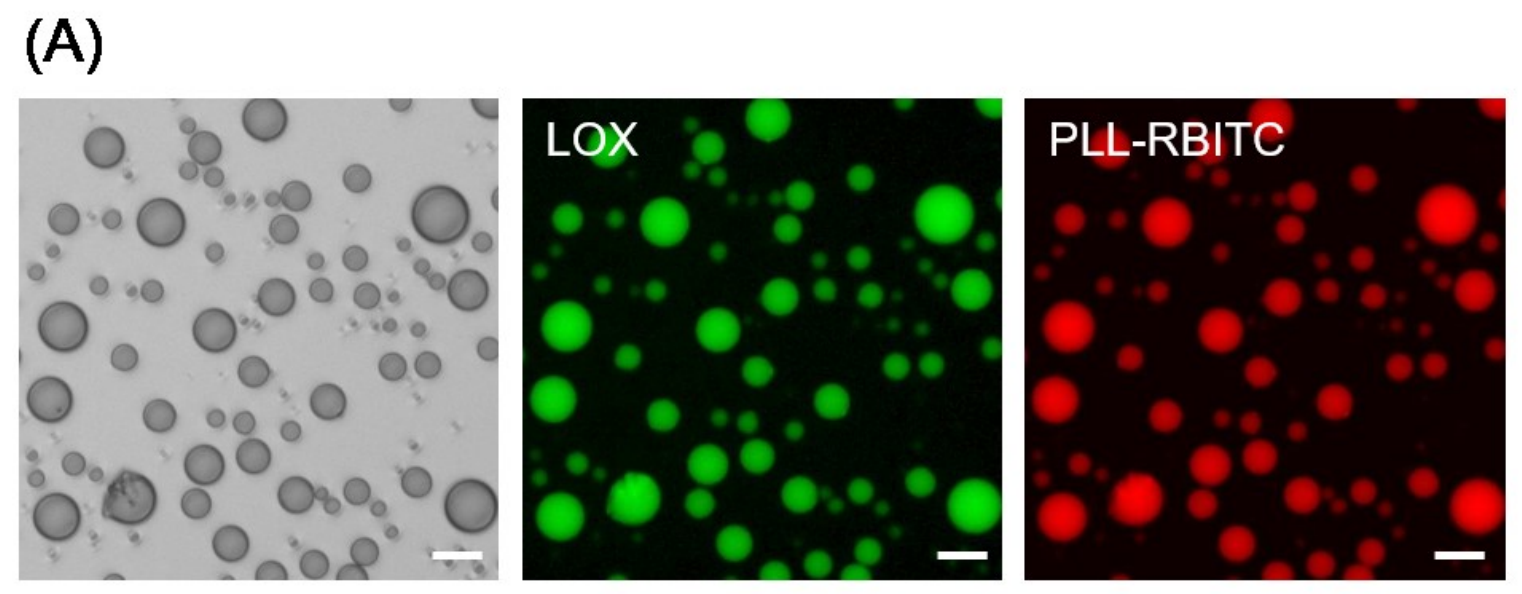

\section{(B)}
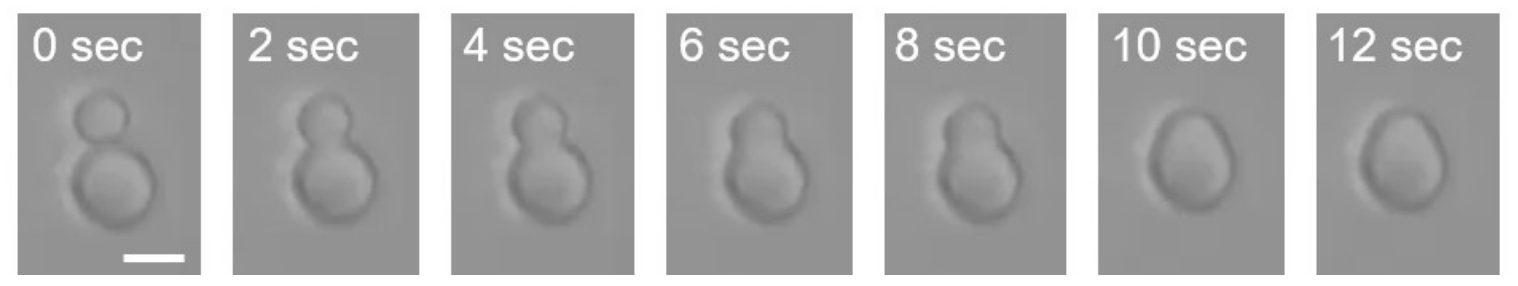

Figure 2. Formation of LOX-PLL droplets.

(A) Bright-field microscopic images of droplets (left) and fluorescent microscopic images of LOX (middle) and PLL-RBITC (right). The solution contained $5 \mu \mathrm{M}$ LOX, $1 \mathrm{mM}$ PLL, $20 \mathrm{mM}$ Tris HCl, and $20 \mathrm{mM}$ MES (pH 8). Scale bar, $20 \mu \mathrm{m}$. (B) Bright-field microscopic images of LOX-PLL droplets. The solution contained $5 \mu \mathrm{M}$ LOX, $1 \mathrm{mM}$ PLL, $20 \mathrm{mM}$ Tris HCl, $20 \mathrm{mM}$ MES (pH 8). Scale bar, $10 \mu \mathrm{m}$. 
(A) PLL concentration

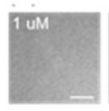

(D) PLL concentration

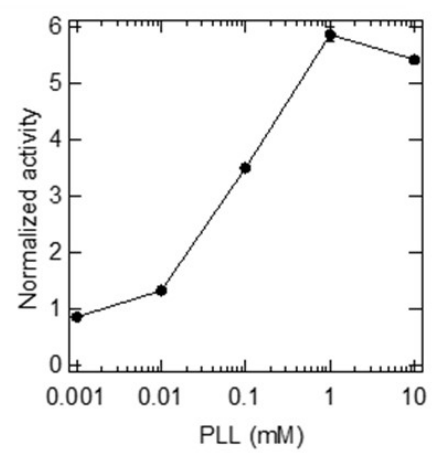

(B) $\mathrm{NaCl}$

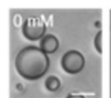

(E) $\mathrm{NaCl}$

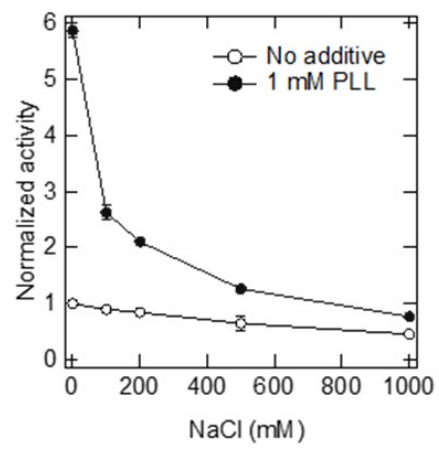

(C) $\mathrm{pH}$

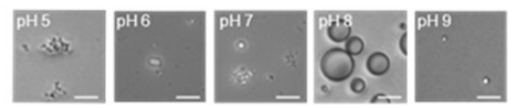

(F) $\mathrm{pH}$

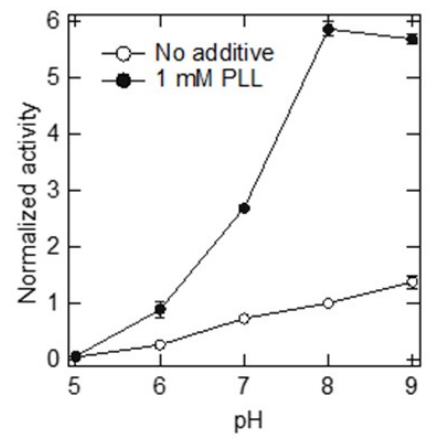

Figure 3. Activation of LOX in liquid droplets under various conditions.

Bright-field microscopic images of LOX-PLL droplets depended on PLL concentration (A), $\mathrm{NaCl}$ concentration (B), and $\mathrm{pH}$ change (C). Scale bar, $10 \mu \mathrm{m}$. Normalized activities of LOX in the presence of LOX-PLL droplets depended on PLL concentration (D), $\mathrm{NaCl}$ concentration (E), and $\mathrm{pH}$ change (F). All solutions contained $5 \mu \mathrm{M}$ LOX, $20 \mathrm{mM}$ Tris $\mathrm{HCl}$, and $20 \mathrm{mM}$ MES. Additionally, 1 $\mathrm{mM}$ PLL $(\mathrm{B}, \mathrm{C})$ and $\mathrm{pH} 8(\mathrm{~A}, \mathrm{~B})$ were tested. The enzyme activity was normalized to the activity of the sample in the absence of PLL (D), in the absence of PLL and $\mathrm{NaCl}(\mathrm{E})$, or in the absence of PLL at $\mathrm{pH} 8(\mathrm{~F})$. 
(B)

(A) LOX concentration
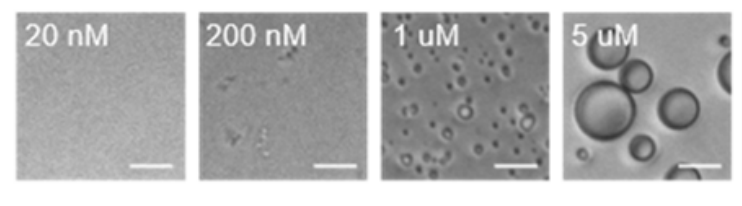

(C)

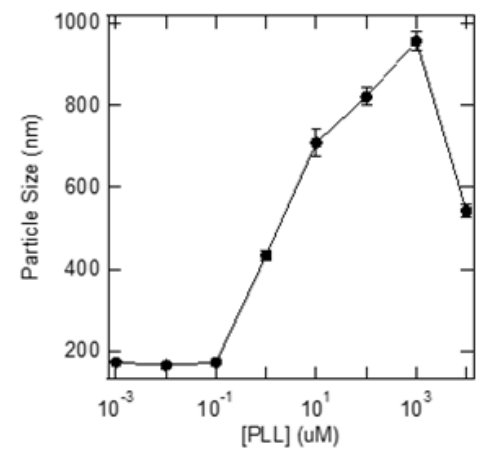

$(\mathrm{F})$

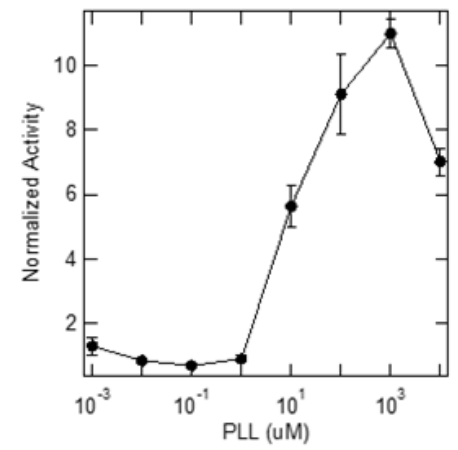

(D)

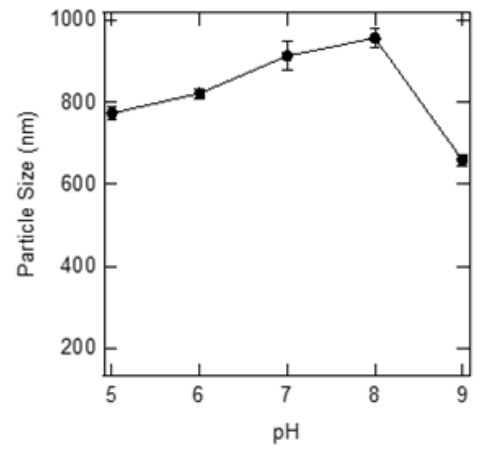

(G)

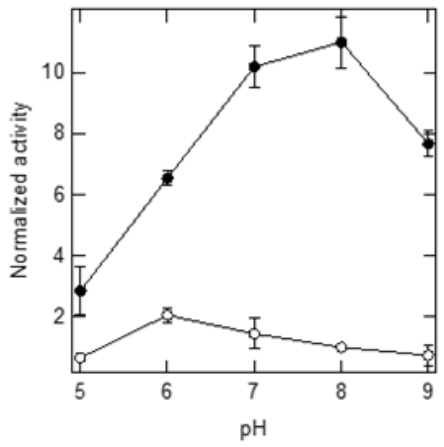

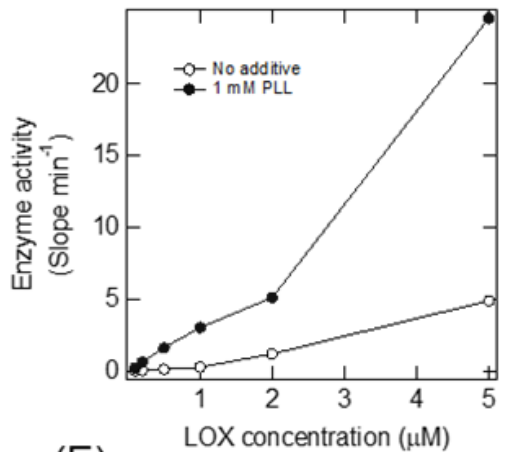

$(\mathrm{E})$

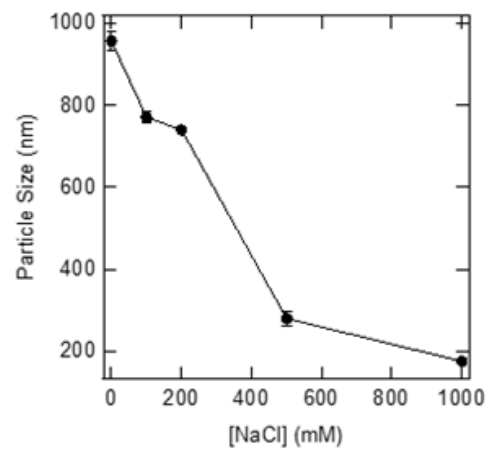

$(\mathrm{H})$

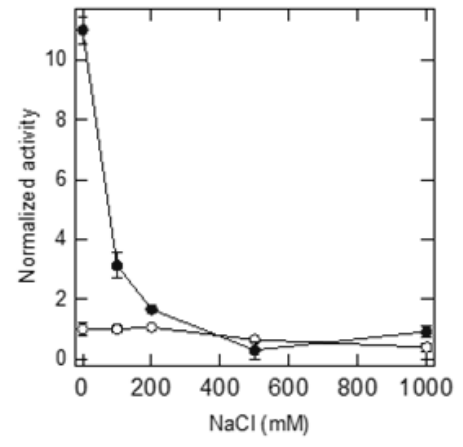

Figure 4. Enzyme activity of LOX in various sizes of liquid droplets

(A) Microscopic images of LOX-PLL droplets depended on LOX concentration. Scale bar, $10 \mu \mathrm{m}$. (B) The enzyme activity of LOX depended on LOX concentration. Particle sizes of LOX-PLL droplets depended on PLL concentration (C), $\mathrm{pH}$ change (D), and $\mathrm{NaCl}$ concentration (E). The normalized activity of LOX in the presence of LOX-PLL droplets de-pended on PLL concentration (F), pH change $(\mathrm{G})$, and $\mathrm{NaCl}$ concentration $(\mathrm{H})$. The enzyme activity was normalized to the activity of the sample in the absence of PLL (F), in the absence of PLL at pH $8(\mathrm{G})$, and in the absence of PLL and $\mathrm{NaCl}(\mathrm{H})$. Closed circles, activity in the presence of PLL; open circles, activity in the absence of PLL (G, H). The concentration of LOX was $20 \mathrm{nM}(\mathrm{C}-\mathrm{H})$. 
bioRxiv preprint doi: https://doi.org/10.1101/2020.12.08.416958; this version posted December 9, 2020. The copyright holder for this preprint (which was not certified by peer review) is the author/funder, who has granted bioRxiv a license to display the preprint in perpetuity. It is made available under aCC-BY-NC-ND 4.0 International license.

Table 1 Michaelis-Menten parameters obtained from nonlinear fitting to the Michaelis-Menten equation

\begin{tabular}{|c|c|c|c|}
\hline PLL $(\mathrm{mM})$ & $k_{\text {cat }}\left(\mathrm{s}^{-1}\right)$ & $\mathrm{K}_{\mathrm{M}}(\mathrm{mM})$ & $k_{\text {cat }} / \mathrm{K}_{\mathrm{M}}$ \\
\hline 0 & $71 \pm 5$ & $1.93 \pm 0.39$ & 37 \\
\hline 1 & $638 \pm 14$ & $0.45 \pm 0.04$ & 1418 \\
\hline
\end{tabular}




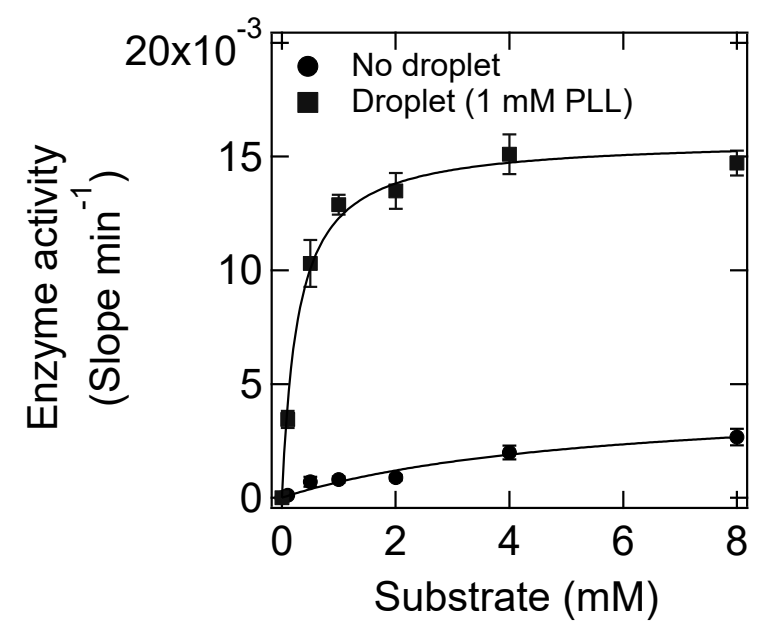

Figure 5. Enzyme kinetics of LOX in the droplets.

The sample solution contained $20 \mathrm{nM}$ LOX, 0 or $1 \mathrm{mM}$ PLL, 0-8 mM L-lactic acid, $20 \mathrm{mM}$ Tris$\mathrm{HCl}$, and $20 \mathrm{mM}$ MES (pH 8). 
bioRxiv preprint doi: https://doi.org/10.1101/2020.12.08.416958; this version posted December 9, 2020. The copyright holder for this preprint (which was not certified by peer review) is the author/funder, who has granted bioRxiv a license to display the preprint in perpetuity. It is made available under aCC-BY-NC-ND 4.0 International license.

(A)

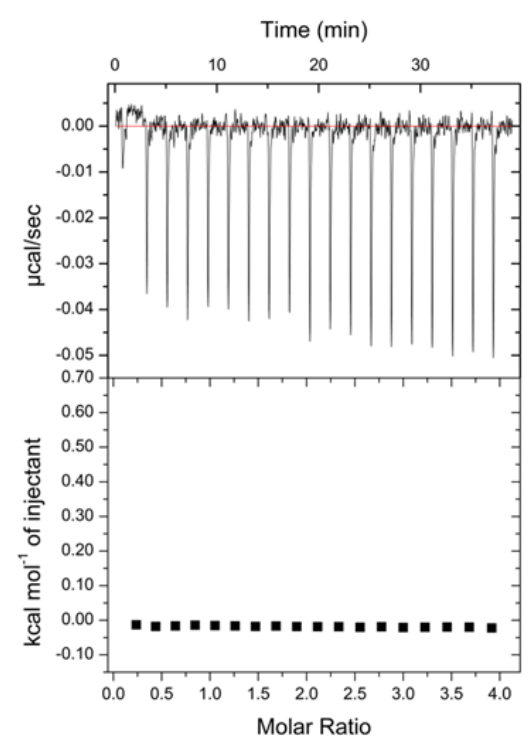

(B)

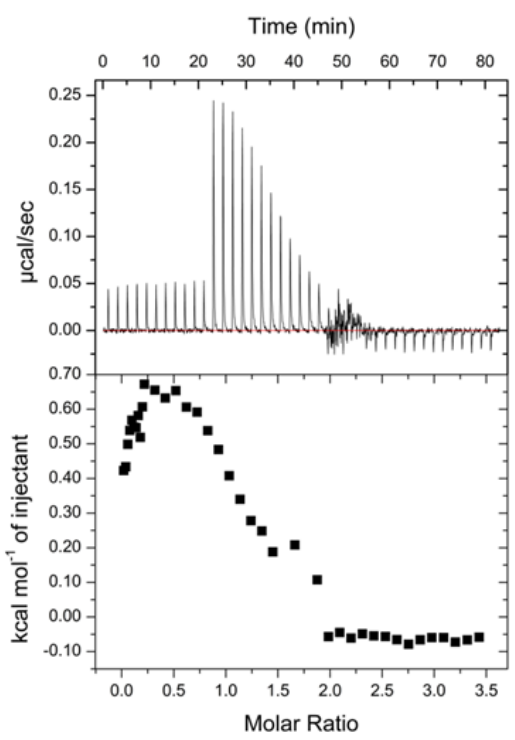

(C)

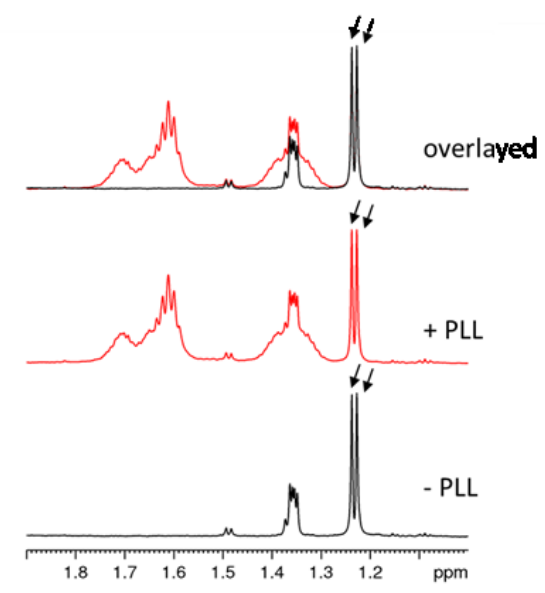

Figure 6. The interaction of PLL with L-lactate.

ITC analysis to quantify the interaction of PLL with L-lactate (A) and LOX (B). (C) 1H-NMR spectra of PLL, L-lactate in the presence and absence of PLL, overlaid. 
(A)

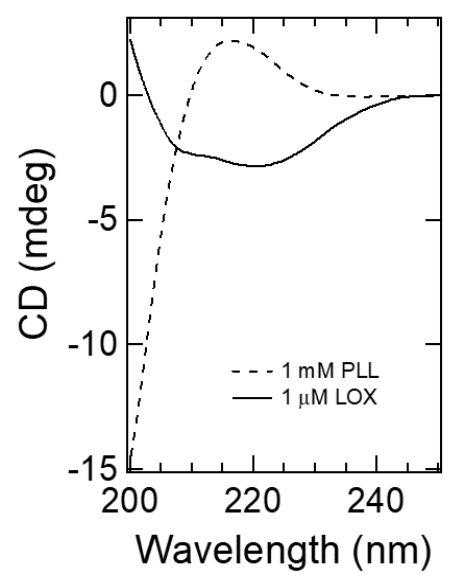

(B)

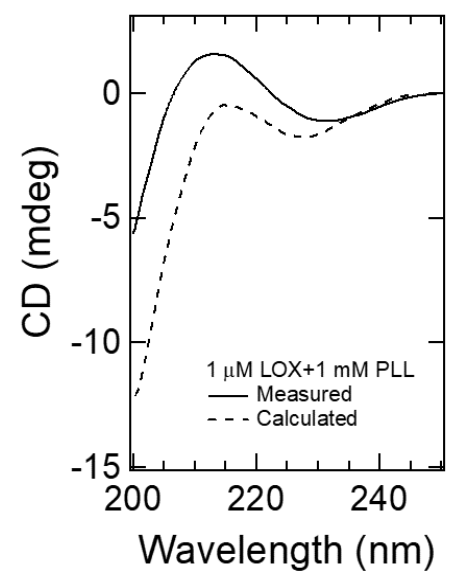

(C)

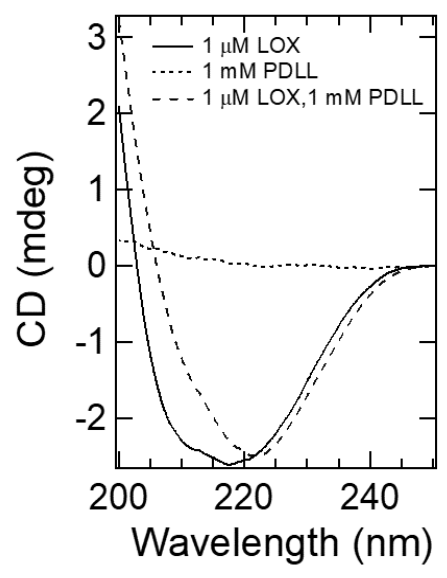

Figure 7. Far-UV CD spectra of LOX and PLL.

(A) CD spectra of $1 \mu \mathrm{M}$ LOX (solid line) and $1 \mathrm{mM}$ PLL (broken line). (B) CD spectra of LOX and PLL mixture (solid line), and CD spectrum calculated from that of LOX and PLL in A (broken line). (C) Far-UV CD spectra of LOX and that with PDLL. 